\section{Incident management systems in disaster management}

Ronald W. Perry
Incident management systems (IMS), particularly in the USA, have received considerable attention since the 11 September 2001 terrorist attacks. US Homeland Security Presidential Directive number 5, a direct response to multi-jurisdictional, multiorganizational challenges arising from the New York City attacks, establishes a national incident management system (NIMS). Prior to this, the California Governor's Office of Emergency Services (Christen et al., 2001) established the California standardized emergency management system (SEMS). For many years, management of wildfires has used or followed the firefighting resources of Southern California organized for potential emergencies (FIRESCOPE) multi-agency coordination system (MACS). Municipal fire departments use the IMS (Brunacini, 1985), and the National Fire Protection Association adopted a standard (NFPA, 2000) on emergency services IMS in 2000. Similarly, the Law Enforcement Incident Command System (LEICS) was systematized and endorsed by the Police Officers Standards and Testing (POST) organization (Bartosh, 2003). On the public health side, the Hospital Emergency Incident Command System (HEICS) originated with the Orange County California Emergency Medical Services Agency and has diffused widely through the medical community.

The issue, however, is not so much one of having some type of IMS, but of actually understanding and using it. Wenger et al. (1989) found that disaster response organizations often spoke of but rarely used IMS. A recent task force of the Council on Foreign Relations (Rudman, 2003) studying first responder capabilities in the USA reported that while use of an IMS would promote successful outcomes and save responder lives, few municipal fire and police departments use the systems except on very large incidents. As Brunacini (2002) argues, an IMS that is not used routinely becomes largely unrehearsed and will be difficult to implement when it is finally used. Some of the lack of use stems from misunderstanding of the principles of IMS and how it fits into a jurisdictional disaster and emergency management system. The purpose of this paper is to review briefly the evolution of IMS, to examine how they can be used at the local jurisdictional level, and to describe the basic logic of incident management. 
Quarantelli (1988) emphasizes that emergency planning and emergency management are very distinct activities. The process of planning and writing the emergency plan itself involves vulnerability assessment, decisions about which potential disasters to manage, reviews of the agentgenerated and response-generated demands made by different agents, inventories of community resources available to meet the demands and the invention of strategies for response. Emergency management refers to the implementation of plans, and the use of personnel and equipment to achieve the tactical and task requirements of response to address a given threat. IMS (of all types) are used to ensure that implementation takes place smoothly and effectively and designed to afford the response flexibility needed to address potential changes in the immediate threat environment. The circumstance that most jurisdictional emergency planners are not first-responders (direct IMS users) often creates confusion about the structure and use of IMS

It is critical to emphasize that all disasters are local events. Natural disasters, technological disasters and terrorist incidents take place within the geography of, or (in the case of telecommunications incidents) produce consequences within one or more local governments. External resources require time to reach local responders; in the USA, locals are warned that federal resources may require 72 hours to arrive (Federal Emergency Management Agency, 2003). Thus, all planning and response begins with local capabilities and resources that later may be supplemented by extra-community capabilities and resources. The agencies that respond to everyday emergencies (motor vehicle accidents, house fires, medical emergencies) are typically the same ones that initiate the response to disasters (larger events that require the coordinated efforts of multiple agencies or jurisdictions). In disasters such as floods or explosions these agencies (fire departments, emergency medical services agencies, or police departments) perform their functions in the context of a sharply different threat. In terrorist attacks there may be a more gradual transition from an apparent emergency to a disaster. For example, emergency medical responders who initially respond to emergency calls for ill citizens may notice "signs and symptoms" which indicate that a biological weapon has been used, thereby necessitating the quick transition to largescale disaster operations. In all these cases, the IMS is the linking structure between response to smaller and larger incidents.

Consequently, there are two fundamental principles for IMS. First, the local response structure must be flexible enough to expand readily as additional resources (particularly from outside the jurisdiction) are added to match the level of demands posed by an escalating event. Second, the IMS used to respond to everyday emergencies will form the basis of an expanded structure to deal with disasters. Thus, the aim of all IMS is to rationalize and organize responders while simultaneously enabling the assimilation of pre-planned resources into the response.

\section{Evolution of the IMS}

The notion of incident command has existed for many years in law enforcement and the fire services as a collection of organizing rules designed to serve the needs of field commanders and operating forces on the front line of emergency response (Kramer and Bahme, 1992, p. 67). Law enforcement agencies tend to use the term incident command systems (ICS), while modern fire services tend to use the term IMS. As indicated above, there are many approaches to, and names for IMS, but all have in common the notion of coordinating the actions necessary to manage disasters and emergencies.

Historically, however, incident command procedures have been both region-specific and idiosyncratic to agencies or disciplines.

The fire services have adopted the principle that fire departments need a common IMS to increase the effectiveness of response. This problem was strongly felt during the early 1980s in Southern California, where large wildfires routinely required the coordinated response of many agencies across many jurisdictions. With funding from the Federal Emergency Management Agency, the FIRESCOPE was formalized. FIRESCOPE is an emergency response system that incorporates both planning functions and the functions of an emergency operations center (EOC).

FIRESCOPE was tailored specifically to large-scale incidents and to the jurisdictional 
structure of Southern California fire services. FIRESCOPE functioned effectively in this capacity and was a major improvement over previous systems (Coleman and Granito, 1988, p. 340; Lesak, 1989). The basic system was very popular and promising, but for several years continued to be used exclusively on large, multi-jurisdictional incidents. With support from the National Fire Protection Association, Alan Brunacini (1985) adapted and enhanced the FIRESCOPE system so that it could be easily used in small events as well as larger ones. Brunacini (1985) changed the command function to include specialized advisors, expanded the operations function to include routine departmental response demands (hazardous materials response, technical rescue, evacuation, etc.) and included explicit connections to a municipal EOC and to police incident commanders. This revised structure was called IMS. A major advantage of Brunacini's (1985) work was that it meant IMS would be used on all incidents under the hypothesis that daily use would enhance the effectiveness of the system when it had to be used in more rare, extremely large incidents. In 2000, the IMS was officially recognized and recommended by the National Fire Protection Association through its standard setting process. IMS is now widely used in the American, Canadian, British and Australian fire services (Buckle et al., 2000). For more than a decade, the Oklahoma State University Fire Services Program and the National Fire Protection Association have provided IMS instruction in the USA and internationally.

A principal aim of IMS is to make all resources of the jurisdiction potentially available for every incident, whether an emergency or a disaster (Perry, 1991, p. 37). The IMS becomes the basic structure into which extra-community resources are integrated when disaster demands outstrip the local jurisdiction's resources. Effective preplanning and pre-identification permits all resources to be provided automatically from a central dispatch, as the response escalates to meet the demands imposed by the incident, as assessed by the incident commander. The IMS itself is a field structure designed to marshal resources at one or more impact scenes. It may or may not be supported by activation of a jurisdictional EOC, depending on the size and complexity of the event. In disasters that are diffuse and present no real geographic location for scene operations, the EOC (utilizing principles of organization from the IMS) can operate alone to guide emergency response. This is important for terrorist attacks involving biological agents where impacts may be detected long after an attack, no single geographic scene may be present and the source and the subject of investigation may be unclear. The strength of using the local IMS (supplemented by a jurisdictional EOC) as the basis for emergency and disaster response lies in its enhancement of the ability to quickly and effectively initiate emergency operations.

When an IMS is routinely used in a jurisdiction, every emergency or disaster is initially addressed by trained and equipped first-responders guided by an incident commander. These personnel are the police, emergency medical responders and firefighters who are always on duty and the initial professional response in threatened communities. Especially in weapons of mass destruction (WMD) terrorist threats, this approach reduces the chance that untrained, unprotected responders will confront an incident and immediately become casualties themselves. Whether an incident is a known disaster (a flood, hurricane, or nuclear power plant accident) or appears to be an emergency which becomes a disaster (an emergency call for "people down" reveals a chemical agent terrorist attack), the IMS is in place and can be expanded to fit situational demands.

\section{IMS in jurisdictional perspective}

For the most part, first-responders are the daily users of the IMS. In a municipal setting, the classic use of IMS is in conjunction with a single event, focused in an identifiable geographical space. This is consistent with the evolution of the IMS as a means of organizing resources for the use of an incident commander and hence its use by fire, police and emergency medical personnel. Most of the work of emergency managers is more global, focused on issues of vulnerability, resources, training, drills and the like. The execution of these tasks follows technical guidelines rather than a form of IMS; in fact they identify both the demands that the IMS must address and the resources available to the IMS. In the case of disasters, response focus often shifts from a localized geographic 
area to an EOC. These events include those involving multiple impact locations (earthquakes), gradual onset events (floods, biological terrorism), or those involving the use of many specialized response agencies across a wide impact area (mass casualty events, wildfires, chemical or radiological terrorism, hazardous materials incidents). The jurisdictional emergency manager typically operates or commands the EOC (which serves as the focal point for assembling and deploying resources). Since the EOC may be organized along the same lines as the IMS, it is in this setting that jurisdictional emergency managers personally use the IMS. While the elements of an IMS organized EOC vary across jurisdictions and threats, the goal remains the same as the IMS in the field: to marshal and deploy the resources and personnel needed to abate the threat agent and manage the consequences of the impact.

\section{Elements of the IMS}

The IMS forms a flexible structure for assembling resources and directing response efforts for managing emergencies and disasters. It is function based rather than agency or responder-identity based. Hence, concern is with activities such as search and rescue, fire suppression, evacuation, hazardous materials identification and abatement, and similar functions needed in a variety of disaster conditions. The system of unity of command under an overall incident commander poses the question of what agency or personnel perform functions less important than the accomplishment of the task itself. Another advantage of the IMS lies in its adaptability to incidents of any size, scope and nature. That is, it functions equally well for events precipitated by fire, medical, hazardous materials, and other demands and it addresses very small, routine incidents as effectively as large, complex, multijurisdictional incidents. As a generic management system, the effectiveness and efficiency of IMS depends on several factors. First, there must be accurate assessment of agent-generated and response-generated demands for the range of threats likely to be faced. Second, the IMS assumes the presence of a cadre of technically trained and adequately equipped response personnel. Third, equipment and response resources paired with appropriate threats, must be identified, located and usually assembled in a centralized location. Fourth, the jurisdiction needs to have the capacity to deploy resources centrally to a scene; in routine emergencies this may be achieved by a dispatch center, while in disasters an EOC performs this function.

Within this context, the IMS is built around responsibilities vested in the role of incident commander (IC). The focus on roles rather than specific individuals or agencies adds still another dimension of flexibility to the system. Thus, any qualified responder may assume the role of IC, though in practice the IC is usually a first-arriving fire company officer or a first-arriving supervisor (fire battalion chief or police sergeant or lieutenant). The philosophy is that there must always be one (and only one) IC at every incident scene, and it is the duty of arriving officers to assume command (except under special circumstances where command may be passed to a senior or specially trained officer). Figure 1 shows a filled out IMS structure, as may be used in fire services, emergency medical operations, or terrorist incidents. The structure begins with the assertion of command and grows (or is filled in) as the IC addresses the hazard. This requires attention to demands raised by the agent (for example, the fire; structural damage; victim rescue, treatment and transportation); and demands raised by supporting the emergency responders (for example, logistics of acquiring needed equipment and supplies; rescue for endangered responders; rehabilitation of responders).

The structure of the IMS uses the terms "sections", "branches" and "sectors" to describe different sized functional groupings of personnel, equipment and apparatus. In Figure 1, Command is shown with five sections directly attached to it. A section is the largest functional grouping, located nearest the incident command officers. These five sections operate as appropriate to the incident size and conditions and include administration, operations, logistics, planning and safety (Brunacini, 2002). Branches are established under sections and represent functional tactical areas relevant to each section. For example, Figure 1 shows five branches under operations: fire, rescue, hazardous materials, medical and transportation. The naming of branches 


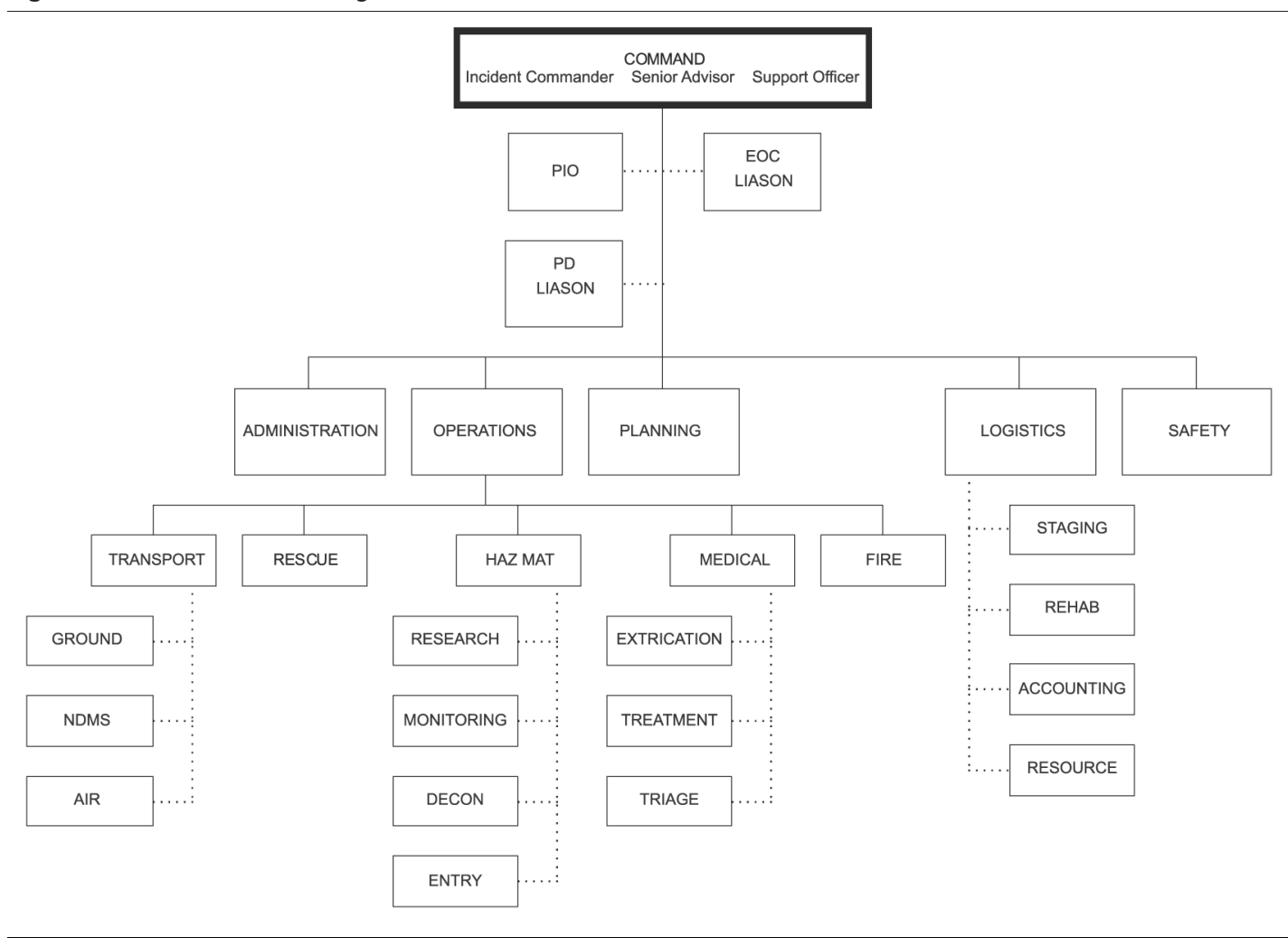

follows their function; the number of branches depends on the functions required in the incident. For example, the IMS for an urban earthquake would include a heavy rescue branch, while a hazardous materials IMS would include an evacuation branch. Sectors are defined beneath branches and execute very specific tasks. Typically, sectors contain fire companies or other special teams. The choice of branch or sector depends on the size or number of demands posed by the incident. Hence, in small hazardous materials incidents with few victims, medical branch may involve a single unit and be called a medical sector. In events where there is no fire, fire branch would not exist. While intuitively easy to grasp, IMS principles are complex, allocating responsibility for response strategy, tactics and tasks. A full exposition can be found in Brunacini (2002). An overview of the IMS follows as a means of demonstrating its effectiveness as an emergency response organizational structure.

Command is vested in the IC, who may be assisted by a support officer and senior advisor. Senior officers typically fill these two roles. The IC first assumes command and establishes a command post. Following this, and throughout the incident, the IC performs seven functions:
(1) conducts initial situation evaluation and continual reassessments;

(2) initiates, maintains and controls communications;

(3) identify incident management strategy, develop an action plan and assign resources;

(4) call for supplemental resources, including EOC activation;

(5) develop an organizational command structure;

(6) continually review, evaluate and revise incident action plan;

(7) provide for continuing, transferring and terminating command.

Through these duties, the IC builds and maintains the strategy and resources that will be needed to manage the scene.

The support officer and senior advisor each review, evaluate and recommend changes to the incident action plan. The support officer addresses tactical priorities, critical factors and safety, creating tactical plans for control and accountability and evaluating the viability of the response organization and span of control. The support officer also evaluates the need for additional resources at the scene. The senior advisor addresses overall incident management, evaluating the need to adapt the incident organization through changes in branches or sectors. The senior advisor also 
evaluates the need for liaison functions with other jurisdictional departments, outside agencies, public officials, property owners, tenants, and other parties affected by the incident. In most jurisdictions, command is supported by an on-scene public information officer (PIO), a liaison to law enforcement or public works command posts and a liaison to the EOC. The goal of an articulated command is to spread the functions to specialists where possible, permit effective communication with responders on scene and emergency authorities off scene, and permit the IC to concentrate on the incident.

The public information sector deals with mass media and provides standard information needed to report accurately the situation. The PIO directs the sector, establishes a media area that does not impede operations, and gathers information about the incident. In a large incident, the on-scene PIO coordinates with the EOC PIO and other responding agencies to ensure consistent, accurate information dissemination and to avoid release of potentially sensitive information.

In complex incidents, particularly terrorist attacks, command assigns a police liaison as a formal link with the police command post (Perry and Lindell, 2003). The police liaison sector deals with all activities requiring coordination between the two departments, including (but not limited to): traffic control, crowd control, scene security, evacuations, and crime scene management.

The remainder of the IMS chart is composed of sections, branches, sectors and units. Sections operate in the command post at the strategy level. The administration section focuses on issues of procurement, cost recovery, liability, and risk management. The planning section is charged primarily with technical liaison, forecasting incident demands, and serves as the "clearinghouse" for information. In terrorist incidents this function is particularly critical because specialized information from a variety of specialists (toxicologists, physicians, chemists, etc.) will flow to the scene, and the planning section becomes the voice of these numerous sources to command.

The logistics section is the support mechanism for the incident response organization. This section oversees a variety of functions and establishes branches or sectors (which operate at a tactical and task level) to execute its functions. Figure 1 shows four principal sectors under logistics:

(1) staging;

(2) accountability;

(3) rehabilitation; and

(4) resources.

Staging oversees the initial arrival and deployment of resources at the scene. Accountability refers to tracking the units and individual crews participating in an incident to ensure their safety. The rehabilitation sector is responsible for monitoring and care of deployed personnel, including physical and psychological condition. This sector uses specialized equipment and also provides food, fluids and debriefing for personnel. Finally, the resource sector oversees all equipment and apparatus, provides communications equipment, and handles repairs and resupply. In terrorist incidents, this sector is usually responsible for supervising the movement of antidotes, other pharmaceuticals and medical supplies and equipment to the scene.

The operations section deals directly with all mitigation activities at the incident site. A critical duty of operations section is to establish branches that coordinate responder actions to accomplish specific tasks to meet incident demands. As many branches as needed are created, depending on the incident demands. Branches typically include primary operational functions: fire, rescue, hazmat, medical, transportation, and evacuation. Fire branch is charged with the management and suppression of fires, and as appropriate operates sectors (a tactical or task level function). Rescue branch is charged with search and rescue and extrication of responders who become lost, trapped or endangered in the incident. An evacuation branch may coordinate the movement of citizens from vulnerable areas adjacent to the scene. The hazardous materials branch typically houses four sectors representing principal functions of research, monitoring, decontamination, and site entry. In a terrorist incident, this branch addresses critical response priorities and performs agent identification, designation of hot, warm and cold zones, and also coordinates with law enforcement resources for site access control and special services (e.g. bomb squad or special weapons and tactics). The entry team sector is responsible for hot zone entry. While emergency decontamination of victims may 
begin with the first units on scene, the hazardous materials branch assembles specialized decontamination lines and equipment and performs technical decontamination.

The medical branch coordinates the activity of sectors and/or units to address extrication, triage, and treatment of patients. The extrication sector is responsible for locating and removing trapped or nonambulatory patients to treatment areas. Triage sector performs the initial assessment of patient conditions and treatment needs. In terrorist incidents, this function may be performed before, simultaneously with, or after decontamination. The toxicity of the agent determines victim assessment and in the case of nerve agents, the timing of the administration of antidotes. Similarly, contingent on the agent, antidote administration may be appropriate at the earliest moment. In such cases treatment and extrication personnel with appropriate personal protective equipment (PPE) would begin administration prior to or during mass decontamination.

Particularly in a terrorist incident, behavioral/mental health usually operates as a sector under the medical branch. The onscene behavioral health coordinator works through the branch officer, while maintaining liaison with the planning section and the EOC if activated. Behavioral health units, with appropriate PPE, may oversee and assist patients awaiting decontamination, during the decontamination process and in treatment and transportation.

The transportation branch can expand to multiple sectors depending on incident demands. Two sectors are usually established in different directional movement points (such as north and south) for ground transportation to local hospitals or other shelters (usually established through the Red Cross). This movement may involve different vehicles as appropriate to patient needs, including busses for uncontaminated or decontaminated "walking wounded", as well as ambulances or other emergency vehicles. The air sector moves patients by rotary wing craft if safe, given the disaster agent involved and required by patient conditions.

Finally, safety is the fifth section in the standard IMS. The safety section officer is responsible for managing safety at the incident. A large part of this work is creating and implementing plans for rescue, scene safety practice and environmental mitigation following operations. Safety section monitors reports from safety officers in different scene locations and reports progress to command. If safety observers uncover a pattern of unsafe practices, the safety officer has the authority to stop operations at a scene.

\section{Conclusion}

In closing, the IMS is a flexible structure for organizing emergency response. The value of understanding the IMS lies in the relationship between emergency operations and emergency planning and plans. To engage adequately in planning for a threat, it is imperative that the structure used to address threats at the scene be taken into account. Since the IMS both reflects and directs the capabilities of the organizations responding to the emergency, planning processes that account for the local IMS have greater flexibility and greater likelihood of being successfully implemented in the field.

\section{References}

Bartosh, D. (2003), Incident Command Management in the Era of Terrorism, Police Executive Research Forum, Washington, DC.

Brunacini, A.V. (1985), Fire Command, National Fire Protection Association, Quincy, MA.

Brunacini, A.V. (2002), Fire Command: The Essentials of IMS, National Fire Protection Association, Quincy, MA.

Buckle, P., Mars, G. and Smale, S. (2000), "New approaches to assessing vulnerability and resilience", Australian Journal of Emergency Management, Winter, pp. 8-14.

Christen, H., Maniscalco, P., Vickery, A. and Winslow, F. (2001), An Overview of Incident Management Systems, Harvard University Belfer Center for Science and International Affairs, Cambridge, MA.

Coleman, R. and Granito, J. (1988), Managing Fire Services, 2nd ed., International City Management Association, Washington, DC.

Federal Emergency Management Agency (2003), Federal Response Plan-9230.1-PL, US Government Printing Office, Washington, DC.

Kramer, W. and Bahme, C. (1992), Fire Officers's Guide to Disaster Control, Pennwell Publishing Company, Saddlebrook, NJ.

Lesak, D. (1989), "Operational decision making", Fire Engineering, Vol. 142 June, pp. 63-9.

National Fire Protection Association (2000), NFPA 1561, Standard on Emergency Services Incident Management System, National Fire Protection Association, Quincy, MA. 
Perry, R.W. (1991), "Managing disaster response operations", in Drabek, T. and Hoetmer, G. (Eds), Emergency Management, International City/County Management Association, Washington, DC, pp. 201-23.

Perry, R.W. and Lindell, M.K. (2003), "Understanding human response to disasters with implications for terrorism", Journal of Contingencies and Crisis Management, Vol. 11, pp. 49-63.
Quarantelli, E.L. (1988), "Disaster crisis management: a summary of research findings", Journal of Management Studies, Vol. 25, pp. 373-89.

Rudman, W. (2003), Emergency Responders: Drastically Underfunded, Dangerously Unprepared, Council on Foreign Relations, Washington, DC.

Wenger, D., Quarantelli, E.L. and Dynes, R. (1989), Disaster Analysis: Police and Fire Departments, Disaster Research Center, University of Delaware, Newark, DE. 